\title{
Early administration of IL-6RA does not prevent radiation-induced lung injury in mice
}

\author{
Toshiyuki Ogata*1, Hideya Yamazaki2, Teruki Teshima³ , Ayaka Kihara³, Yuko Suzumoto33, Takehiro Inoue1, \\ Norihiro Nishimoto 4 and Nariaki Matsuura ${ }^{5}$
}

\begin{abstract}
Background: Radiation pneumonia and subsequent radiation lung fibrosis are major dose-limiting complications for patients undergoing thoracic radiotherapy. Interleukin-6 (IL-6) is a pleiotropic cytokine and plays important roles in the regulation of immune response and inflammation. The purpose of this study was to investigate whether anti-IL-6 monoclonal receptor antibody (IL-6RA) could ameliorate radiation-induced lung injury in mice.
\end{abstract}

Methods: BALB/CAnNCrj mice having received thoracic irradiation of 21 Gy were injected intraperitoneally with IL-6RA (MR16-1) or control rat lgG twice, immediately and seven days after irradiation. Enzyme-linked immunosorbent assay was used to examine the plasma level of IL-6 and serum amyloid A (SAA). Lung injury was assessed by histological staining with haematoxylin and eosin or Azan, measuring lung weight, and hydroxyproline.

Results: The mice treated with IL-6RA did not survive significantly longer than the rat IgG control. We observed marked up-regulation of IL-6 in mice treated with IL-6RA 150 days after irradiation, whereas IL-6RA temporarily suppressed early radiation-induced increase in the IL-6 release level. Histopathologic assessment showed no differences in lung section or lung weight between mice treated with IL-6RA and control.

Conclusions: Our findings suggest that early treatment with IL-6RA after irradiation alone does not protect against radiation-induced lung injury.

\section{Background}

Radiation pneumonia, an interstitial pulmonary inflammation, and subsequent radiation lung fibrosis are significant dose-limiting complications and may threaten quality of life for patients receiving radiation to the thorax. Radiation pneumonia and/or pulmonary fibrosis occur in approximately $10-20 \%$ of patients treated with thoracic radiotherapy [1]. The incidence of radiationinduced lung toxicity has increased in recent years due to more aggressive therapies such as combined chemoradiotherapy [2]. Clinical symptoms range from cough, fever, and shortness of breath to death from respiratory failure. At the cellular and tissue level, radiation pneumonia presents as an edema of the interstitial space, infiltration of inflammatory cells, and thickening of the alveolar septa.

Although the molecular mechanism for radiation pneumonia is complex and obscure, involvement of proin-

* Correspondence: ogata@radonc.med.osaka-u.ac.jp

1 Department of Radiation Oncology, Osaka University Graduate School of Medicine, 2-2 Yamadaoka, Suita, Osaka, Japan

Full list of author information is available at the end of the article flammatory cytokines, chemokines, and cell adhesion molecules has been implicated [3,4]. Many investigators have shown that cytokines play essential roles in the pathogenesis of radiation pneumonia [5,6]. Interleukin-6 (IL-6), which was originally identified as a B-cell differentiation factor [7], is now known to be a multifunctional cytokine that regulates acute phase response, immune response, and inflammation $[8,9]$. IL- 6 is produced by a variety of cells such as $T$ cells, B cells, monocytes, macrophages, fibroblasts, endothelial cells, and several tumor cells [10]. Clinical as well as experimental findings have suggested the involvement of IL-6 as a pro-inflammatory cytokine in radiation pneumonia [11-14]. Indeed, up-regulation of IL-6 production has been observed in human and animals with radiation pneumonia.

In this study, we examined the effect of anti-IL-6 monoclonal receptor antibody (IL-6RA) on radiation-induced lung injury in mice having received lethal irradiation of the whole thorax. We investigated whether IL-6RA treatment would offer the promise of a new pharmacologic 
intervention strategy for ameliorating radiation-induced lung injury.

\section{Methods}

\section{Mice and irradiation}

Eight-week-old specific pathogen-free female BALB/ cAnNCrj mice were obtained from Charles River 1-2 weeks before testing. Mice were maintained according to the institutional animal care use committee guidelines. The mice were anesthetized by i.p. injection of pentobarbital $(40 \mathrm{mg} / \mathrm{kg})$ immediately before irradiation. The whole thorax was irradiated by $4 \mathrm{MV} \mathrm{X}$-ray from the linear accelerator (Mitsubishi, EXL-6SP) at a dose of 21 Gy with a delivered dose rate of approximately $1.8 \mathrm{~Gy} / \mathrm{min}$ and a 1.0-cm bolus material on the surface. The field was $2.5 \mathrm{~cm}$ in length in the cephalic-tail direction. Survival and body mass were monitored in IL-6RA treatment $(\mathrm{n}=$ 7) or control $(n=8)$ mice for 200 days after 21 Gy irradiation. For other assays, the animals were sacrificed at a predetermined time of 50,100, and 150 days after irradiation ( $\mathrm{n}=5$ per group). Any mouse showing signs of distress, including lethargy, hunched back, or increased breathing frequency was sacrificed by overdose of pentobarbital.

\section{Injection of IL-6RA(MR16-1)}

Basic characterizations of the rat anti-mouse IL-6 receptor monoclonal antibody, MR16-1, have been detailed in previously published reports [15]. Immediately and 1 week after irradiation, mice were intraperitoneally administered with a single doses of MR16-1 $(8 \mathrm{mg} / \mathrm{kg}$ body weight) or with the same volume and concentration of purified rat IgG (ICN Biomedicals, Inc).

\section{Circulating IL- 6 and SAA analysis}

Blood samples were collected via cardiac puncture at the time of euthanasia, and plasma was obtained after microcentrifugation at 4,000 g for $5 \mathrm{~min}$. Plasma concentrations of IL-6 (Pierce Endogen Co. Ltd) and serum amyloid A (SAA) (Biosource) were measured by commercial enzyme-linked immunosorbent assay (ELISA) kits according to the instructions of the manufacturer.

\section{Lung hydroxyproline determination}

Collagen deposition was estimated by determining the hydroxyproline content of the left lung. Samples were hydrolyzed with $6 \mathrm{~N} \mathrm{HCl}$ at $105^{\circ} \mathrm{C}$ for $18 \mathrm{~h}$. The samples were resuspended in $2 \mathrm{ml}$ of deionized water and $1 \mathrm{ml}$ of chloramine $\mathrm{T}$ dissolved in $5 \mathrm{~mol} / \mathrm{L}$ sodium acetate/10\% isopropanol. Next, $0.5 \mathrm{ml}$ of Ehrlich's reagents were added, mixed, and incubated at $65^{\circ} \mathrm{C}$ for $10 \mathrm{~min}$. The absorbance of the solutions at $562 \mathrm{~nm}$ was determined. The hydroxyproline values of the samples were calculated according to comparing to the standard curve. Data were corrected for total left lung wet weight.

\section{Histologic analysis}

For histological examination, the lung tissue was fixed in $10 \%$ neutral-buffered formalin solution, embedded in paraffin wax, sectioned (5 $\mu \mathrm{m}$ thickness), and stained with haematoxylin and eosin (H\&E) or Azan. For H\&E staining, we evaluated an edema of the interstitial space, infiltration of inflammatory cells, thickening of the alveolar septa, and vessel thrombosis. The amount of pulmonary interstitial collagen was determined by Azan staining. The area stained blue (collagen fibers) was evaluated under a microscope.

\section{Statistical analysis}

The statistical significance was tested by means of the Kaplan-Meier method and the log-rank test for survival analysis. Comparison of the other assays between two groups was performed using non-parametric the MannWhitney U-test because of small number. A p-value of less than 0.05 was considered to be statistically significant.

\section{Results}

\section{Survival and body weight}

We first evaluated whether IL-6RA administration leads to increased survival of mice exposed to lethal thoracic irradiation and found that the mice treated with IL-6RA did not survive significantly longer than the rat IgG control (Figure 1A). Growth expressed as total body weight is presented graphically in Figure 1B, showing that the mice treated with IL-6RA tended to weigh more than the rat IgG control mice.

\section{IL-6 and SAA concentrations}

Protein levels of IL-6 and SAA, one of the major acutephase proteins in mammals, were determined by means of specific ELISA in plasma from irradiated mice (Figure 2 ). The mice treated with IL-6RA showed a marked reduction of the radiation-induced increase in IL- 6 proteins in plasma as compared with the control group 50 days $(25.1 \pm 10.5$ versus $101.6 \pm 31.2 \mathrm{pg} / \mathrm{ml}, \mathrm{p}<0.05)$ and 100 days $(48.5 \pm 17.2$ versus $446.3 \pm 96.9 \mathrm{pg} / \mathrm{ml}, \mathrm{p}<0.05)$ after irradiation (Figure 2A). After 150 days, however, a marked, but not statistically significant, up-regulation in IL-6 was observed in mice treated with IL-6RA in comparison with the rat IgG group $(247.6 \pm 116.6$ versus $116.9 \pm 56.4 \mathrm{pg} / \mathrm{ml}$ ). As shown in Figure 2B, administration of IL-6RA significantly suppressed the radiationinduced increase in SAA proteins in plasma compared with the control group after 150 days $(10.9 \pm 8.8$ versus $101.1 \pm 32.7 \mu \mathrm{g} / \mathrm{ml}, \mathrm{p}<0.05)$. Non-irradiated mice without any antibody in a previous study showed low IL- 6 and SAA protein levels in plasma $(25.2 \pm 7.7 \mathrm{pg} / \mathrm{ml}$ and $8.2 \pm$ $4.4 \mu \mathrm{g} / \mathrm{ml}$, respectively). 
A

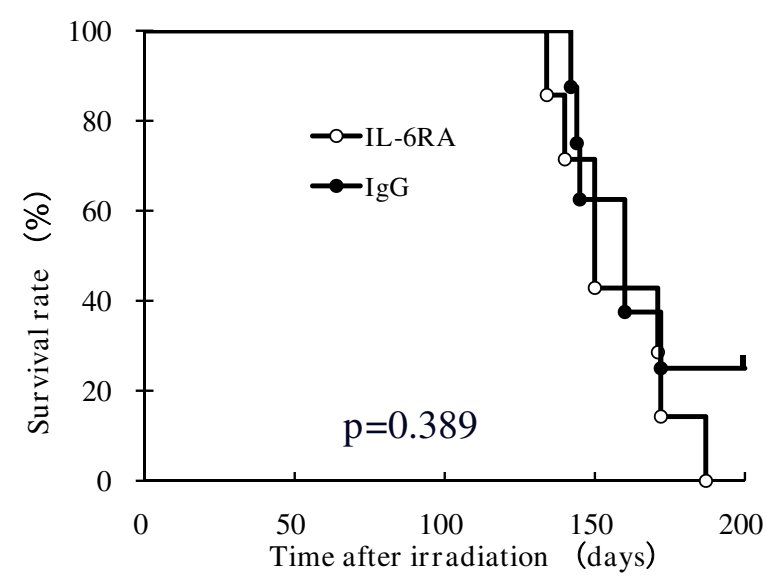

$\mathrm{B}$

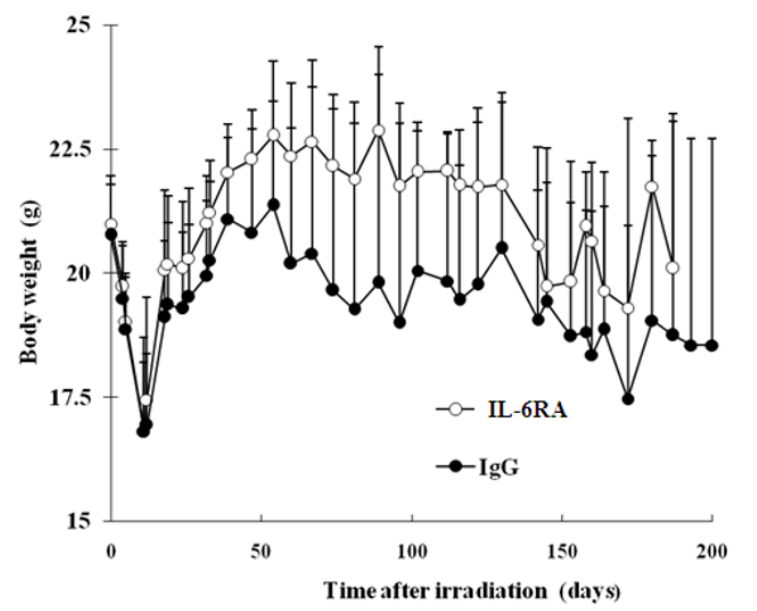

Figure 1 Kaplan-Meier analysis of survival curves and body weights for IL-6RA- (white circle) and IgG control (black circle)-injected mice. (A) Survival curves. The $p$ value was calculated with the log-rank test. Kaplan-Meier plots were calculated from data for 7 IL-6RA-treated mice and 8 nontreated mice. (B) Body weights. Data are presented as means + SD.

\section{Wet lung weights and hydroxyproline content}

Lung weight was measured to assess pulmonary edema and consolidation (Figure 3A) and after lung irradiation a gradual, time-dependent increase in lung weight was observed in the IL-6RA group as compared with the control group. However, the difference in lung weight between the two groups did not become significant at any time after irradiation.

Lung hydroxyproline measurements were analyzed for the quantification of collagen deposition (Figure 3B) and no statistically significant difference in hydroxyprolin content between the two groups was detected after irradiation.

\section{Histologic analysis}

The time course of H\&E and Azan staining in the lung tissue after irradiation is shown in Figures 4 and 5, demonstrating that the extent and severity of lung damage was not significantly reduced in the IL-6RA group in comparison with the control group.
A

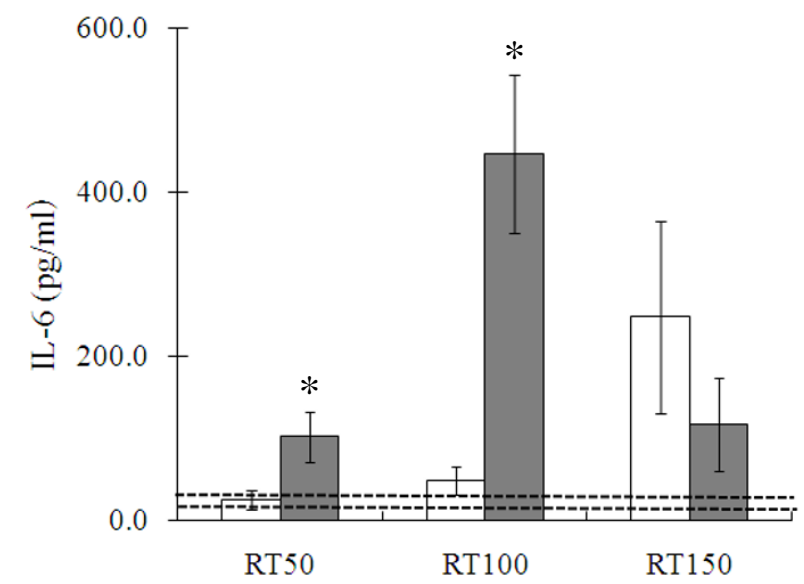

B

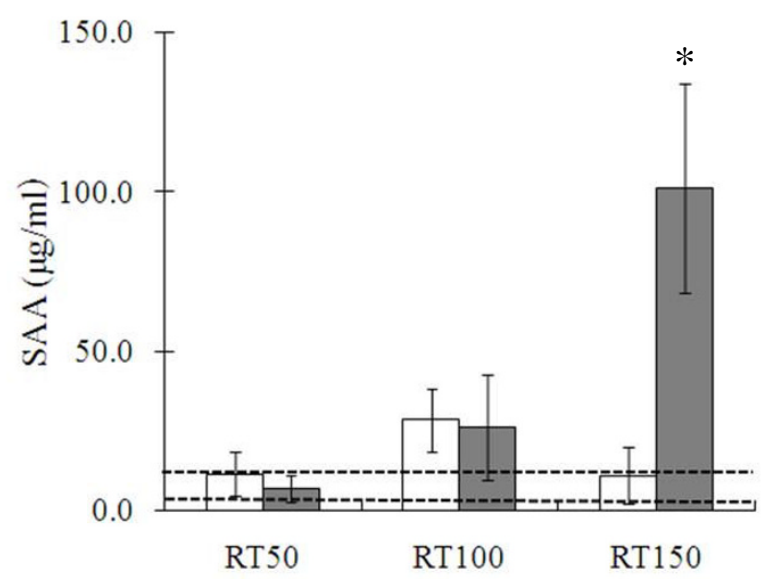

Figure 2 Effects of IL-6RA treatment in lungs of lethally irradiated IL-6RA (white square) and IgG control (black square) mice on radiationinduced increases in IL-6 (A) and SAA (B) production. Each bar represents the mean \pm SD ( $n=5$ per group). Asterisks indicate statistical significance. Dotted line represents each from average value of non-irradiated mice + SD to average value of them -SD. 
A

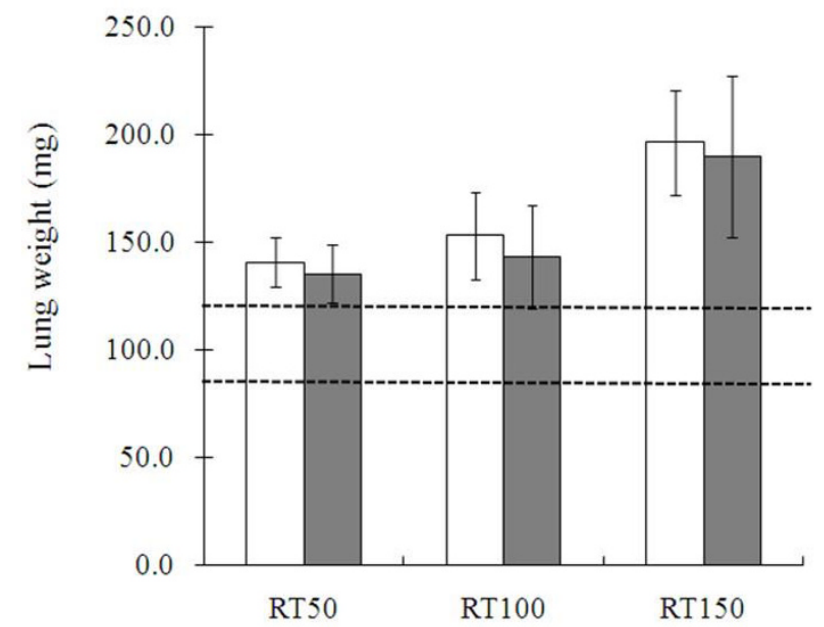

B

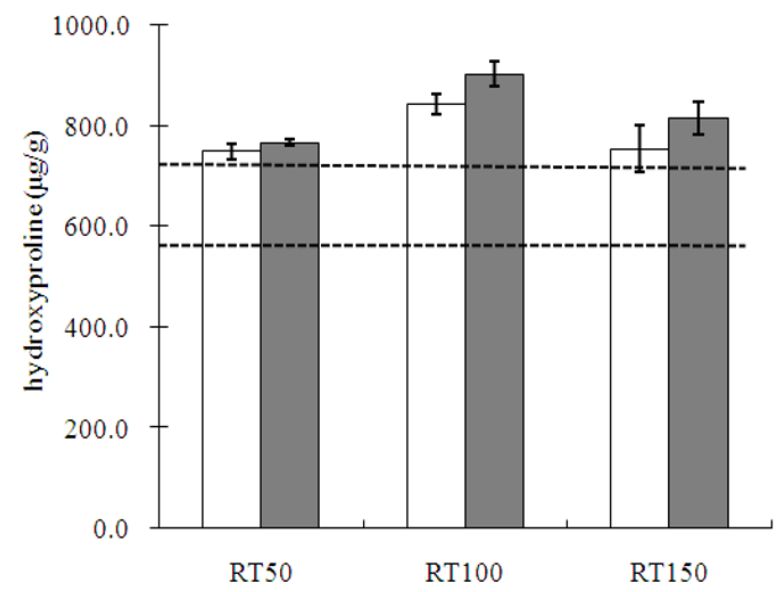

Figure 3 Effects of IL-6RA treatment on radiation-induced lung injury indices. (A) Lung weight after 21 Gy of single irradiation to whole thorax with (white square) or without (black square) IL-6RA treatment. (B) Hydroxyproline levels in lung homogenates obtained from IL-6RA injected mice (white square) or control (black square). Data obtained from 5 animals in each group are presented as means \pm SD. Dotted line shows each from mean value of non-irradiated mice + SD to mean value of them $-S D$.

\section{Discussion}

Radiation pneumonia and subsequent radiation lung fibrosis are major dose-limiting complications for patients undergoing thoracic radiotherapy. Recent research findings support the existence of a mechanism of cellular interaction between lung parenchymal cells and circulating immune cells mediated through various cytokines such as proinflammatory cytokines, chemokines, adhesion molecules, and profibrotic cytokines [3,4].

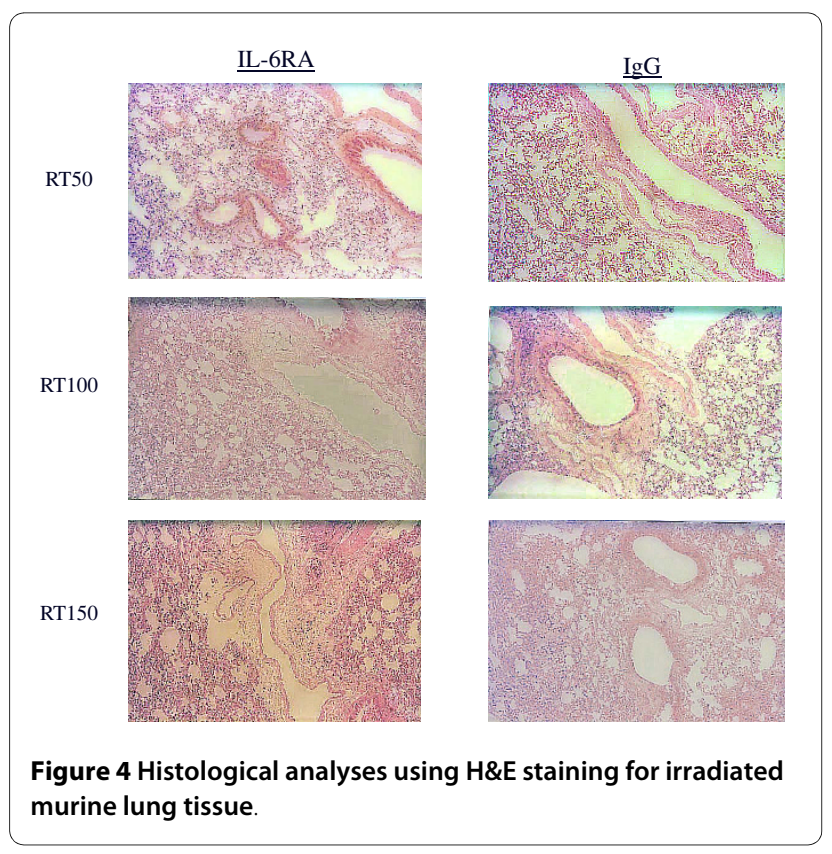

Since IL-6 is a pleiotropic cytokine that plays important roles in the regulation of immune response and inflammation, IL-6 receptor monoclonal antibody treatment has been identified as a promising treatment for Castleman's disease, rheumatoid arthritis, juvenile idiopathic arthritis, and Crohn's disease [16-19]. IL-6 has also been implicated in the pathogenesis of radiation pneumonia [11-14] and is synthesized by type II pneumocytes, alveolar macrophages, T lymphocytes, and lung fibroblasts [5].

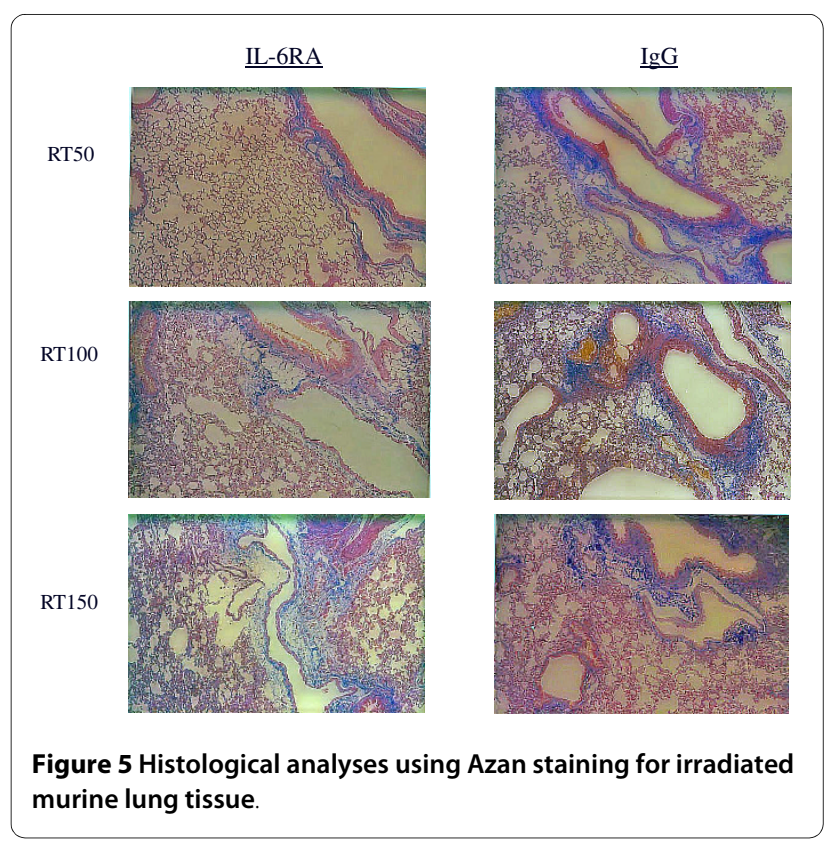


We therefore hypothesized that blockage of the IL-6 signaling pathways may offer an attractive therapeutic target for the amelioration of radiation-induced lung injury.

IL-6RA treatment was found to inhibit a radiationinduced increase in IL- 6 proteins 50 and 100 days after irradiation. Moreover, after 150 days IL-6RA significantly suppressed a radiation-induced increase in inflammatory marker SAA proteins in plasma as compared with the control group. Acute phase protein SAA is known as a sensitive systemic marker of inflammation and tissue damage [20]. Further, IL-6 plays an important role in the synergistic induction of the SAA gene and the anti-IL-6 receptor monoclonal antibody inhibits the synergistic induction of SAA [21]. These findings indicate that IL6RA has some beneficial effects. In our study, however, no significant difference was observed in severity of lung damage or length of survival between IL-6RA treated mice and control.

One possible explanation for this finding is that longterm continuous administration of IL-6RA may be necessary for reducing lung toxicity. Rube et al. showed that radiation-induced release of IL- 6 in the bronchiolar epithelium of C57BL/6J mice was detected a few hours and several weeks after irradiation (peak at 8 weeks) [14]. Radiation-induced lung injury is a chronic phenomenon mediated by various cells such as inflammatory cells responding to the release or activation of downstream cytokines, growth factors, or chemokines. Anscher et al. reported long-term (6-month) administration of the small molecule inhibitor of TGF-beta was more effective in reducing radiation-induced lung toxicity than shortterm (3-week) administration [22]. Long-term IL-6RA treatment following irradiation may therefore ameliorate radiation-induced lung injury. Because we were concerned that repeated treatment with rat antibody would result in the production of mouse anti-rat antibodies against the rat antibody, we could not administer IL-6RA more than twice. In a previous pilot study we examined plasma IL-6 levels in mice having received only radiation of 21 Gy and confirmed that radiation-induced IL-6 production in Balb/c mice reached a peak 1 week after irradiation (data not shown). The reason for the choice of this time point was that we wanted to inhibit acute interstitial inflammation.

A marked up-regulation of IL- 6 was observed in mice treated with IL-6RA in comparison with the rat IgG group 150 days after irradiation. This result may be explained by the fact that the time until the peak concentration of IL-6 in IL-6RA-treated mice had changed due to the inhibition of autocrine production of IL-6. Rube $e t$ al. reported radiation-induced IL-6 production in C57BL/6J mice reached two peaks a few hours and 8 weeks after irradiation [14]. However, marked mouse strain differences in cytokine levels and patterns may occur such as in the histological configuration of radiation-induced lung injury [23]. BALB/c mice were chosen for this study because this strain is known to possess comparable radiosensitity [24]. We hypothesized that use of a different mice strain might cause changes in the pathogenesis of radiation pneumonia and thus alter the survival of mice receiving lethally irradiation of the whole thorax. A significant increase in SAA was observed in mice treated with IgG in comparison with the IL-6RA group 150 days after irradiation, whereas the mice treated with IL-6RA showed a significant induction of IL-6 in comparison with the rat IgG group. This result may be explained by the fact that signal transduction of IL-1 or TNF-alpha is more strongly involved in the regulation of SAA production than that of IL-6 [25]. These findings suggest that elevation of IL- 6 was not strongly implicated in the pathogenesis of radiation pneumonia but was rather derived from the development of radiation pneumonia. Although a limitation of our study is that a relatively small number of mice were used, it is clear from these results that further intensive study is warranted.

There is concern that intervention to prevent radiationinduced toxicity may also serve to protect cancer because clinical investigations found increased serum IL-6 levels in cancer patients [26]. Aberrant production and signaling of circulating IL- 6 has been implicated in tumor generation and poor disease outcome in various cancers [27]. Since blockade of IL-6 signaling by shRNA inhibits lung adenocarinoma cell growth [28], IL-6RA treatment may inhibit radiation-induced lung toxicity as well as tumor proliferation.

\section{Conclusions}

To summarize, the findings presented here suggest that early intervention using IL-6RA could not ameliorate radiation-induced lung injury. Additional work is needed to determine the optimal timing and duration for therapy using this approach to the prevention of lung injury after radiation therapy. Despite the negative findings of our study, further intensive studies are needed into strategies for inhibition of cytokine signaling as a way to ameliorating lung toxicity from radiotherapy.

\section{Competing interests}

The authors declare that they have no competing interests.

\section{Authors' contributions}

TO carried out the animal experiments and drafted the manuscript. AK and YS performed the animal experiments. TT and IT participated in the statistical analysis. $\mathrm{HY}, \mathrm{NN}$, and MN conceived of the study, and participated in its design and coordination and helped to draft the manuscript. All authors read and approved the final manuscript.

\section{Acknowledgements}

The authors are indebted to Kumie Hirai, Atsuko Kawaguchi, and Kimiko Sameshima for excellent technical support. 


\section{Author Details}

'Department of Radiation Oncology, Osaka University Graduate School of Medicine, 2-2 Yamadaoka, Suita, Osaka, Japan, ${ }^{2}$ Department of Radiology, Graduate School of Medical Science, Kyoto Prefectural University of Medicine, Kajiicho, Kawaramachi Hirokoji, Kamigyo-ku, Kyoto, Japan, ${ }^{3}$ Medical Physics \& Engineering, Osaka University Graduate School of Medicine, 2-2 Yamadaoka, Suita, Osaka, Japan, ${ }^{4}$ Laboratory of Immune Regulation, Wakayama Medical University, Saito-asagi, Ibaraki, Osaka, Japan and 5 Functional Diagnostic Science, Osaka University Graduate School of Medicine, 2-2 Yamadaoka, Suita Osaka, Japan

\section{Received: 29 November 2009 Accepted: 7 April 2010}

Published: 7 April 2010

\section{References}

1. Mehta V: Radiation pneumonitis and pulmonary fibrosis in non-smallcell lung cancer: pulmonary function, prediction, and prevention. Int $J$ Radiat Oncol Biol Phys 2005, 63:5-24.

2. Yu TK, Whitman GJ, Thames HD, Buzdar AU, Strom EA, Perkins GH, Schechter NR, McNeese MD, Kau SW, Thomas ES, Hortobagyi GN, Buchholz TA: Clinically relevant pneumonitis after sequential paclitaxelbased chemotherapy and radiotherapy in breast cancer patients. $J$ Natl Cancer Inst 2004, 96:1676-1681.

3. Tsoutsou PG, Koukourakis MI: Radiation pneumonitis and fibrosis: mechanisms underlying its pathogenesis and implications for future research. Int J Radiat Oncol Biol Phys 2006, 66:1281-1293.

4. Brush J, Lipnick SL, Phillips T, Sitko J, McDonald JT, McBride WH: Molecular mechanisms of late normal tissue injury. Semin Radiat Oncol 2007, 17:121-130

5. Rubin P, Johnston CJ, Williams JP, McDonald S, Finkelstein JN: A perpetual cascade of cytokines postirradiation leads to pulmonary fibrosis. Int $\mathrm{J}$ Radiat Oncol Biol Phys 1995, 33:99-109.

6. Chen Y, Williams J, Ding I, Hernady E, Liu W, Smudzin T, Finkelstein JN, Rubin P, Okunieff P: Radiation pneumonitis and early circulatory cytokine markers. Semin Radiat Oncol 2002, 12(Suppl 1):26-33.

7. Hirano T, Yasukawa K, Harada H, Taga T, Watanabe Y, Matsuda T, Kashiwamura S, Nakajima K, Koyama K, Iwamatsu A: Complementary DNA for a novel human interleukin (BSF-2) that induces B lymphocytes to produce immunoglobulin. Nature 1986, 324:73-76.

8. Naka T, Nishimoto N, Kishimoto T: The paradigm of IL-6: from basic science to medicine. Arthritis Res 2002, 4(Suppl 3):233-242.

9. Nishimoto N, Kishimoto T: Inhibition of IL-6 for the treatment of inflammatory diseases. Curr Opin Pharmacol 2004, 4:386-391.

10. Kishimoto T, Akira S, Narazaki M, Taga T: Interleukin- 6 family of cytokines and gp130. Blood 1995, 86:1243-1254.

11. Chen Y, Rubin P, Williams J, Hernady E, Smudzin T, Okunieff P: Circulating IL- 6 as a predictor of radiation pneumonitis. Int J Radiat Oncol Biol Phys 2001, 49:641-648.

12. Chen Y, Hyrien O, Williams J, Okunieff $P$, Smudzin T, Rubin P: Interleukin (IL)-1A and IL-6: applications to the predictive diagnostic testing of radiation pneumonitis. Int J Radiat Oncol Biol Phys 2005, 62:260-266.

13. Rube CE, Wilfert F, Palm J, Konig J, Burdak-Rothkamm S, Liu L, Schuck A, Willich N, Rube C: Irradiation induces a biphasic expression of proinflammatory cytokines in the lung. Strahlenther Onkol 2004, 180:442-448.

14. Rube CE, Uthe D, Wilfert F, Ludwig D, Yang K, Konig J, Palm J, Schuck A, Willich N, Remberger K, Rube C: The bronchiolar epithelium as a prominent source of pro-inflammatory cytokines after lung irradiation. Int J Radiat Oncol Biol Phys 2005, 61:1482-1492.

15. Okazaki M, Yamada Y, Nishimoto N, Yoshizaki K, Mihara M: Characterization of anti-mouse interleukin-6 receptor antibody. Immunol Lett 2002, 84:231-240.

16. Nishimoto N, Yoshizaki K, Miyasaka N, Yamamoto K, Kawai S, Takeuchi T, Hashimoto J, Azuma J, Kishimoto T: Treatment of rheumatoid arthritis with humanized anti-interleukin- 6 receptor antibody: a multicenter, double-blind, placebo-controlled trial. Arthritis Rheum 2004 50:1761-1769.

17. Yokota S, Miyamae T, Imagawa T, Iwata N, Katakura S, Mori M, Woo P, Nishimoto N, Yoshizaki K, Kishimoto T: Therapeutic efficacy of humanized recombinant anti-interleukin- 6 receptor antibody in children with systemic-onset juvenile idiopathic arthritis. Arthritis Rheum 2005, 52:818-825.
18. Nishimoto N, Kanakura Y, Aozasa K, Johkoh T, Nakamura M, Nakano S, Nakano N, Ikeda Y, Sasaki T, Nishioka K, Hara M, Taguchi H, Kimura Y, Kato Y, Asaoku H, Kumagai S, Kodama F, Nakahara H, Hagihara K, Yoshizaki K, Kishimoto T: Humanized anti-interleukin-6 receptor antibody treatment of multicentric Castleman disease. Blood 2005, 106:2627-2632.

19. Ito H, Takazoe M, Fukuda Y, Hibi T, Kusugami K, Andoh A, Matsumoto T, Yamamura T, Azuma J, Nishimoto N, Yoshizaki K, Shimoyama T, Kishimoto T: A pilot randomized trial of a human anti-interleukin- 6 receptor monoclonal antibody in active Crohn's disease. Gastroenterology 2004, 126:989-996.

20. Gabay C, Kushner I: Acute-phase proteins and other systemic responses to inflammation. N Engl J Med 1999, 340:448-454.

21. Hagihara K, Nishikawa T, Isobe T, Song J, Sugamata Y, Yoshizaki K: IL-6 plays a critical role in the synergistic induction of human serum amyloid A (SAA) gene when stimulated with proinflammatory cytokines as analyzed with an SAA isoform real-time quantitative RTPCR assay system. Biochem Biophys Res Commun 2004, 314:363-369.

22. Anscher MS, Thrasher B, Zgonjanin L, Rabbani ZN, Corbley MJ, Fu K, Sun L, Lee WC, Ling LE, Vujaskovic Z: Small molecular inhibitor of transforming growth factor-beta protects against development of radiation-induced lung injury. Int J Radiat Oncol Biol Phys 2008, 71:829-837.

23. Sharplin J, Franko AJ: A quantitative histological study of straindependent differences in the effects of irradiation on mouse lung during the early phase. Radiat Res 1989, 119:1-14

24. Ponnaiya B, Cornforth MN, Ullrich RL: Radiation-induced chromosomal instability in BALB/C and C57BL/6 mice: the difference is as clear as black and white. Radiat Res 1997, 147:121-125

25. Raynes JG, Eagling S, McAdam KP: Acute-phase protein synthesis in human hepatoma cells: differential regulation of serum amyloid $A$ (SAA) and haptoglobin by interleukin-1 and interleukin-6. Clin Exp Immunol 1991, 83:488-491.

26. Trikha M, Corringham R, Klein B, Rossi JF: Targeted anti-interleukin-6 monoclonal antibody therapy for cancer: a review of the rationale and clinical evidence. Clin Cancer Res 2003, 9:4653-4665.

27. Hodge DR, Hurt EM, Farrar WL: The role of IL-6 and STAT3 in inflammation and cancer. Eur J Cancer 2005, 41:2502-2512.

28. Gao SP, Mark KG, Leslie K, Pao W, Motoi N, Gerald WL, Travis WD, Bornmann W, Veach D, Clarkson B, Bromberg JF: Mutations in the EGFR kinase domain mediate STAT3 activation via IL-6 production in human lung adenocarcinomas. J Clin Invest 2007, 117:3846-3856.

doi: $10.1186 / 1748-717 \mathrm{X}-5-26$

Cite this article as: Ogata et al., Early administration of IL-6RA does not prevent radiation-induced lung injury in mice Radiation Oncology 2010, 5:26

\section{Submit your next manuscript to BioMed Central and take full advantage of:}

- Convenient online submission

- Thorough peer review

- No space constraints or color figure charges

- Immediate publication on acceptance

- Inclusion in PubMed, CAS, Scopus and Google Scholar

- Research which is freely available for redistribution 